\title{
Characteristics of protein variants in trichlorphon-resistant Bactrocera dorsalis (Diptera; Tephritidae) larvae
}

\author{
T. Jin ${ }^{1,2}$, L. Zeng ${ }^{1}$, Y.-Y. Lin ${ }^{1,2}$, Y.-Y. Lu ${ }^{1}$ and G.-W. Liang ${ }^{1}$
}

${ }^{1}$ Laboratory of Insect Ecology, College of Natural Resources and Enviornment, South China Agricultural University, Guangzhou, China

${ }^{2}$ Key Laboratory of Monitoring and Control of Tropical Agricultural and Forest Invasive Alien Pests, Ministry of Agriculture,

Environment and Plant Protection Institute,

Chinese Academy of Tropical Agricultural Sciences, Danzhou, China

Corresponding author: Y.-Y. Lu / G.-W. Liang

E-mail: luyongyue@scau.edu.cn / gwliang@scau.edu.cn

Genet. Mol. Res. 11 (3): 2608-2619 (2012)

Received November 28, 2011

Accepted May 16, 2012

Published July 10, 2012

DOI http://dx.doi.org/10.4238/2012.July.10.12

\begin{abstract}
Functional proteins in larvae of Bactrocera dorsalis, a major fruit pest, play a central role in their resistance to organophosphorus insecticides. Changes in proteins in $B$. dorsalis larvae after trichlorphon treatment may have a role in the resistance response to trichlorphon. We analyzed 14 protein spots of crude proteins from $B$. dorsalis larvae post-treatment with trichlorphon in two-dimensional gel electrophoresis through mass spectrometry and protein sequencing. We found functional proteins that are responsible for signal transduction (pkaap and dual specificity tyrosine-phosphorylation-regulated kinase), immunity (hemolectin), synthesis and decomposition (twinstar, cathepsin B,
\end{abstract}


RE66325p), oxidative stress metabolism (glutathione S transferase and CG7320), energy metabolism (Act57B), and cytoskeleton formation (actin). These proteins appear to be involved in the resistance response to trichlorphon.

Key words: Insecticide resistance; Bactrocera dorsalis; Trichlorphon; Two-dimensional gel electrophoresis; Mass spectrometry

\section{INTRODUCTION}

The resistance of insects to pesticides is one of the most serious problems in crop protection. Organophosphorus compounds are extensively used for pest control due to their broad-spectrum toxicity and potent eradication of the target insect pests in the past decades. In general, one function is to inhibit acetylcholinesterase with subsequent accumulation of acetylcholine at nerve endings. The specific change in the structure of acetylcholinesterase can lead to resistance. The mutations in the gene (ace) encoding the acetylcholinesterase are associated with resistance to organophosphorus pesticides (Fournier et al., 1992). Another function is to induce delayed polyneuropathy through organophosphorus pesticides, which is related to the inhibition of esterase activity of neuropathy targets (Johnson, 1982). In addition, the metabolic mechanisms of insect reaction to organophosphorus compounds are involved in antioxidant defense and lipid peroxidation in cytotoxicity (Ranson et al., 2002; Akhgari et al., 2003). However, the correlation between the resistance response of insects after organophosphorus compound treatment and the change in protein expression level is still limited.

The oriental fruit fly, Bactrocera dorsalis (Hendel) (Diptera: Tephritidae) is one of the most notorious pests of tropical and subtropical fruits and vegetables (Steiner, 1957; Ye and Liu, 2005). It was documented in Taiwan in 1912 for the first time, and later observed in most Asian-Pacific regions (Steiner, 1957). Due to internal feeding by the larvae and adult traits including high mobility and spread capacity, high fecundity, and strong flying behavior, $B$. dorsalis is considered as a fangled pest in Southeast Asia. Broad-spectrum insecticides have been used to control $B$. dorsalis, especially organophosphorus pesticides. On mainland China, at least 10 colonies of $B$. dorsalis collected from the field exhibited middle-level resistance to trichlorphon (organophosphorus insecticide) (Jin et al., 2011). The resistance rate of the laboratory strain to trichlorphon is equal or higher than that to cypermethrin (pyrethroid pesticide) and avermectin (microbial pesticide) (Pan et al., 2008). This result indicates that the susceptibility of $B$. dorsalis to organophosphorus compounds is unstable.

Two-dimensional (2-DE) gel electrophoresis and mass spectrometry (MS) can provide powerful characterization of the proteins of interest. Recently, the change in protein variants in insects induced by infections, such as parasitoid attack, and chemical compound toxicity, has been investigated by using the 2-DE method (Candas et al., 2003; Huang et al., 2004; Nguyen et al., 2008; Song et al., 2008). The identification of proteins in the oriental fruit fly at different periods after insecticide application will provide more useful information of biologically important molecules to explore trichlorphon toxicity. In the present study, our objective was to explore the response of $B$. dorsalis to trichlorphon 
exposure at the protein level for comparing physiological and metabolic changes after different induction time. Fourteen specific proteins expressed in the larvae of $B$. dorsalis were separated and identified. Consequently, the identified proteins were classified into six functional groups. These results will extend the further understanding of the repertoire of functional molecules with the toxicity of organophosphorus pesticides.

\section{MATERIAL AND METHODS}

\section{Oriental fruit fly strain}

The insect species B. dorsalis was originally collected in 2004 from Guangzhou, China. Approximately 1500 larvae were collected from carambola and transported to the insect rearing room. A banana and maize-based artificial diet (containing $150 \mathrm{~g}$ corn gain, $150 \mathrm{~g}$ banana, 0.6 g sodium benzoate, $30 \mathrm{~g}$ yeast, $30 \mathrm{~g}$ sucrose, $30 \mathrm{~g}$ winding paper, $1.2 \mathrm{~mL} \mathrm{HCl}$ and $300 \mathrm{~mL}$ $\mathrm{H}_{2} \mathrm{O}$ ) was used to feed the insects (Jin et al., 2011). The rearing conditions were $25^{\circ} \pm 1{ }^{\circ} \mathrm{C}$, a light period of $16 \mathrm{~L}: 8 \mathrm{D}$ and $70-80 \%$ humidity. In the experiment, trichlorphon was provided by Nantong Agrochemical Co. Inc. (Nantong City, Jiangsu Province, China).

The median lethal concentration $\left(\mathrm{LC}_{50}\right)$ was determined by the residual contact method. The powder of trichlorphon was diluted in acetone with seven different concentrations. The test solutions for each concentration was $5 \mathrm{~mL}$ and used to coat the inner wall of $250-\mathrm{mL}$ conical flasks after rolling the flask until the acetone was evaporated completely. Ten adult flies, 3-5 days old, were placed in each flask in triplicate. Mortality was recorded after trichlorphon treatment for $24 \mathrm{~h}$. The control group was subjected to the same treatment without trichlorphon. Raw bioassay data were analyzed through probit analysis by using Statistical Analysis System (SAS) to calculate $\mathrm{LC}_{50}$ (Stark, 2005). To establish the resistant strain, the third instar larvae were soaked at the working dilutions at the $\mathrm{LC}_{50}$ dose for $2 \mathrm{~s}$ and adult flies were treated at the same working dilutions by using residual contact method for $1 \mathrm{~h}$. Surviving adult flies were used for rearing, and the $\mathrm{LC}_{50}$ was then determined every 3 generations. The $\mathrm{LC}_{50}$ was $89.2 \mathrm{mg} / \mathrm{L}$ for the $\mathrm{F}_{39}$ generation of $B$. dorsalis after resistance selection for trichlorphon.

\section{Insect treatment with insecticide for protein extraction}

The larvae (approximately 100-110 mg body weight) were starved for 2-3 $\mathrm{h}$, and then soaked at $89.2 \mathrm{mg} / \mathrm{L}$ trichlorphon solution $\left(\mathrm{LC}_{50}\right)$ for $2 \mathrm{~s}$. The blank control was resistant strains and treated with pure acetone alone. The behavior of test insects was observed after treatment for $2 \mathrm{~h}$. Surviving larvae were chosen and the insecticide-treated insects were collected at 3,6 and $12 \mathrm{~h}$. The controls were chosen after treatment for 3 and $6 \mathrm{~h}$. Insect bodies with total weight of $0.15 \mathrm{~g}$ were collected from each group.

\section{Sample preparation}

For 2D-PAGE, insects were killed and frozen with liquid nitrogen. Insect bodies were homogenized in a lysis buffer containing $8 \mathrm{M}$ urea, $2 \mathrm{M}$ thiourea, $0.02 \mathrm{M}$ Tris base, $30 \mathrm{mM}$ DTT, 4\% CHAPS, and 1\% IPG buffer, $\mathrm{pH} 4-7$. Chilled mortar and pestle were 
used to extract whole proteins. The supernatant after centrifugation at $3000 \mathrm{rpm}$ for $5 \mathrm{~min}$ was used as the crude protein sample. After precipitation in TCA/acetone, the protein concentrations were determined (Bradford, 1976). Bovine serum album (BSA) was used as the protein standard.

\section{2-DE and gel staining}

A $340-\mu \mathrm{L}$ sample (containing $150 \mu \mathrm{g}$ protein) was dehydrated on the $18 \mathrm{~cm} \mathrm{IPG}$ strips ( $\mathrm{pH}$ 4-7 from Amersham) for $12 \mathrm{~h}$ at $20^{\circ} \mathrm{C}$ and constant voltage of $50 \mathrm{~V}$. Isoelectric focusing (IEF) was carried out at $200 \mathrm{~V}$ for $200 \mathrm{Vh}, 500 \mathrm{~V}$ for $500 \mathrm{Vh}, 1000 \mathrm{~V}$ for $1000 \mathrm{Vh}$, and $8000 \mathrm{~V}$ for $43,000 \mathrm{Vh}$ at $20^{\circ} \mathrm{C}$. Maximum current was set at $50 \mu \mathrm{A} /$ strip in an IEF unit from Multiphor (Amersham Biosciences). Following IEF, the IPG strip was equilibrated for $15 \mathrm{~min}$ in $375 \mathrm{mM}$ Tris, $\mathrm{pH} 8.8$, containing $6 \mathrm{M}$ urea, 20\% (v/v) glycerol, $2 \%(\mathrm{w} / \mathrm{v})$ SDS, and $130 \mathrm{mM}$ DTT. DTT was replaced with $260 \mathrm{mM}$ iodoacetamide. The IPG strips were then sealed with $1 \%$ agarose in SDS running buffer at the top of slab gels ( $200 \times 175$ x $1 \mathrm{~mm})$, which were polymerized with mixed acrylamide (10\%) and N,N'-methylenebisacrylamide $(0.01 \%)$. The second-dimensional electrophoresis was performed at $8^{\circ} \mathrm{C}$ in a vertical electrophoresis bath (at $14 \mu \mathrm{A}$ for $1 \mathrm{~h}$, and then $28 \mu \mathrm{A}$ for $4 \mathrm{~h}$ ).

\section{Imaging analysis}

Preparative gels were stained with a silver-stain compatible MS/MS protocol (Shevchenko et al., 1996) and scanned by ImageScanner ${ }^{\mathrm{TM}}$ (Amersham Biosciences). Three or four repetitions were performed. The ImageMaster ${ }^{\mathrm{TM}}$ 2D Platinum version 5.0 software (Amersham, Biosciences) was used for quantitative analysis. Proteins were analyzed in triplicate to confirm overall reproducibility of the protein spot pattern. After choosing one reference gel, the protein spots were matched automatically across gels, and the background was subtracted manually. The protein spots were normalized by using the mean volume of three unchanged spots under two conditions. The selective criteria for these gels were the absence of significant distortion. The confidence threshold for the up- and downregulated protein spots was set at 3- to 4-fold of the spot intensity in anyone treatment when compared to the control.

\section{In-gel digestion and mass spectrometry}

Protein spots of interest were excised from the gels. The gel slices were washed with $100 \mu \mathrm{L}$ double-distilled $\mathrm{H}_{2} \mathrm{O}$ three times, and then distained with $25 \mu \mathrm{L} 30 \mathrm{mM} \mathrm{K}_{3} \mathrm{Fe}(\mathrm{CN})_{6}$ and $25 \mu \mathrm{L} 100 \mathrm{mM} \mathrm{NaS}_{2} \mathrm{O}_{3}$ for $1 \mathrm{~min}$. The gel slices were dehydrated using $100 \%(\mathrm{w} / \mathrm{v})$ acetonitrile at room temperature. The gel slices were then crushed and dried after $0.02 \mu \mathrm{g} /$ $\mu \mathrm{L}$ Trypsin (Promega, USA) digestion in $5 \mu \mathrm{L} 100 \mathrm{mM} \mathrm{NH}_{4} \mathrm{HCO}_{3}$ solution at $37^{\circ} \mathrm{C}$ for 16 $18 \mathrm{~h}$. The digested peptides were extracted from gel slices with $0.1 \%$ trifluoroacetic acid (TFA) in $50 \%(\mathrm{v} / \mathrm{v})$ acetonitrile/water.

The identification of the isolated proteins was performed using a Finnigan LTQ mass spectrometer (ThermoQuest, San Jose, CA, USA) coupled with a Surveyor HPLC system (Thermo Quest). First, a Microcore RP column (C18: 0.15 x 120 mm; ThermoHypersil, San 
Jose, CA, USA) was used to separate the digested proteins, where $0.1 \%(\mathrm{v} / \mathrm{v})$ formic acid and $0.1 \%(\mathrm{v} / \mathrm{v})$ formic acid in $100 \%(\mathrm{v} / \mathrm{v})$ CAN were used as solvent $\mathrm{A}$ and $\mathrm{B}$, respectively. The gradient was started at $2 \%$ solvent B for $15 \mathrm{~min}$, and increased linearly up to $98 \%$ solvent B within $90 \mathrm{~min}$. The peptides were eluted from the C18 microcapillary column at a flow rate of $150 \mu \mathrm{L} / \mathrm{min}$, and then electrosprayed directly into the mass spectrometer with the application of a spray voltage of $3.2 \mathrm{kV}$ under the capillary temperature of $170^{\circ} \mathrm{C}$. The full scanning range was M/Z 400 to 2000 .

\section{Database searching}

Protein identification using MS/MS raw data was performed with the SEQUEST software (University of Washington, licensed to Thermo Finnigan) based on the SwissPort database (Tu et al., 2005; Zhou et al., 2007). A relative molecular mass of 57 Da was used for the average molecular mass of cisterns in MS/MS data searching. Both $b$ and $y$ ions were also included in the database searching. The results of protein identification were filtered with the Xcorr $(1+\geq 1.9,2+\geq 2.2,3+\geq 3.75)$ and DelCn $(\geq 0.1)$.

\section{Identification of protein functions}

The searching results were used as a reference to explain the possible functions of proteins (http://flybase.org and http://blast.ncbi.nlm.nih.gov/Blast.cgi). The E-value was less than 1.00E-30 as the significant hit for selecting an insect protein rather than an equally matched primate protein. The theoretical and experimental $\mathrm{pI}$ data were not always consistent and these discrepancies could be attributed to post-translational modifications, multiple protein isoforms, and different protein compositions.

\section{RESULTS}

\section{2-DE profiles for protein variants from $B$. dorsalis larvae}

Approximately 400 individual spots (corresponding to proteins with molecular sizes ranging from 14 to $100 \mathrm{kDa}$ and isoelectric points from $\mathrm{pI} 4$ to 7) were resolved by 2-DE PAGE, as shown in Figure 1. No significant change in protein expression level was observed in acetone treatment alone for 3 or $6 \mathrm{~h}$. Four gels from the control group and post-treatment for 3, 6 and $12 \mathrm{~h}$ were analyzed by the ImageMaster ${ }^{\mathrm{TM}} 2 \mathrm{D}$ Platinum analysis software. Approximately 50 proteins revealed different expression levels between the treatment groups and the control group. Meanwhile, 26 proteins exhibited a significant difference. Among these 26 proteins, 9 proteins with a significantly higher expression level and 5 proteins with a significantly lower expression level were observed in the treatment groups.

\section{Protein identification}

To examine the homology of protein variants from different organisms, 14 protein spots were subjected to Q-TOF and MS analysis. The possible functions of these proteins including D3, D4, D5, U2, U3, U4, U7, and U8 were identified through BLAST searching (Table 1). 
Resistance response to organophosphorus insecticides

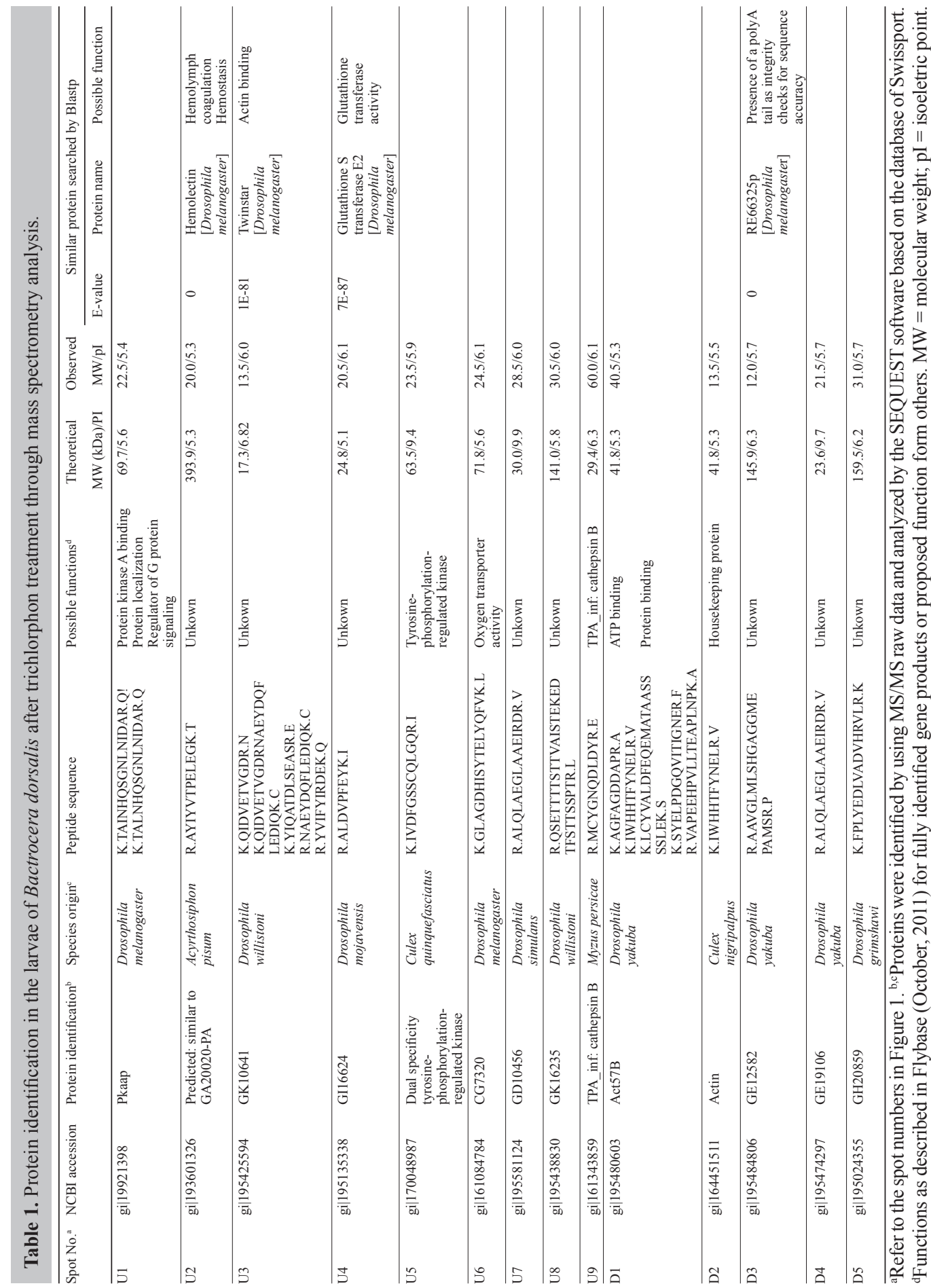




\section{Functional classification of different proteins}

A total of 14 spots representing the candidate responsive proteins induced by trichlorphon were identified, as shown in Figure 1. All identified proteins could be classified into six functional groups including signaling, immunity, protein synthesis, oxidative metabolism, energy metabolism, and cytoskeleton. The upregulated and downregulated proteins are shown in Figure 2. However, some proteins, including U7, U8, D4, and D5, could not be identified.

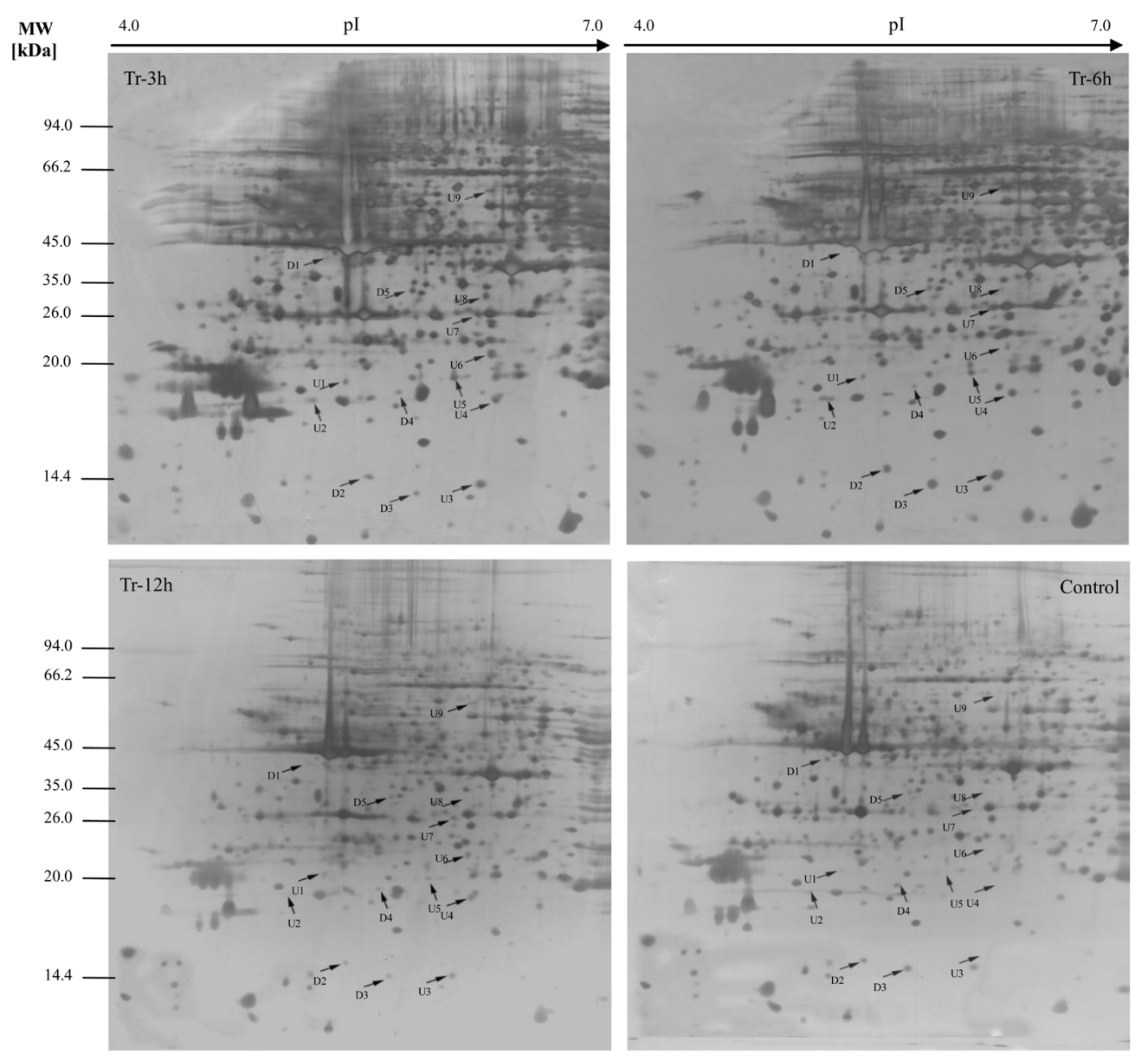

Figure 1. Representative two-dimensional gels revealed the separation of the proteins in Bactrocera dorsalis after trichlorphon treatment. The proteins were prepared after trichlorphon treatment at $\mathrm{LC}_{50}$ dose for $3(\mathrm{Tr}-3 \mathrm{~h}), 6(\mathrm{Tr}-$ $6 \mathrm{~h})$, and $12 \mathrm{~h}(\mathrm{Tr}-12 \mathrm{~h})$ as well as acetone treatment alone as the control. The proteins were separated by isoelectric points $(\mathrm{pI})$ in first dimension and then by molecular weights $(\mathrm{MW})$ in the second dimension. Four gels were run on the $\mathrm{pH}$ range of 4-7 and the resultant pattern was overlapped. Spots U1-U9 and D1-D5 represent the up-regulated and down-regulated proteins as the response to the toxicity of trichlorphon. 


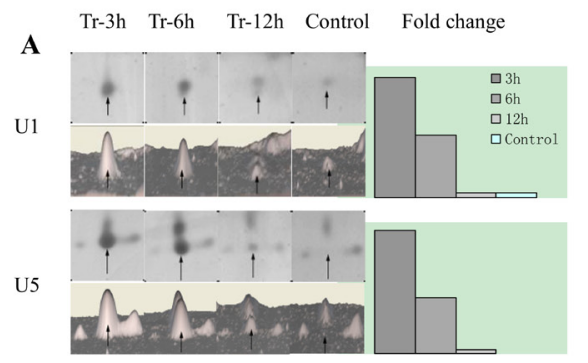

C

U3

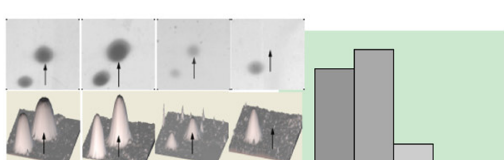

U9

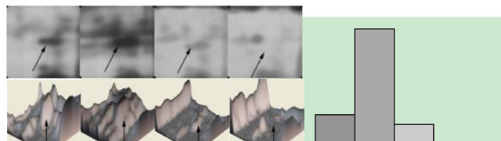

D3

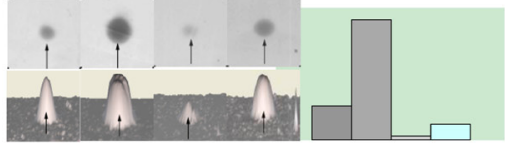

E

D1

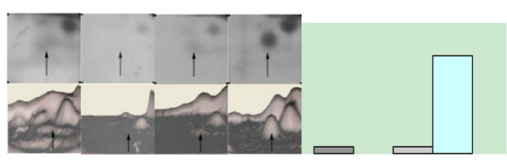

F

D2

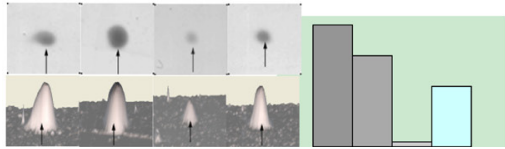

B

Tr-3h $\quad$ Tr-6h $\quad$ Tr-12h Control Fold change

U2

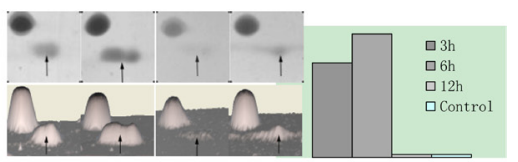

D

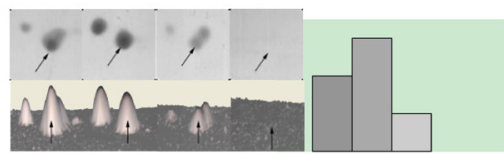

U6

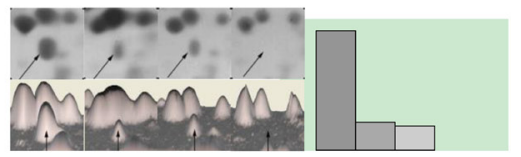

$\mathbf{G}$

U7

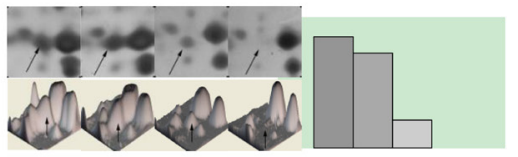

U8

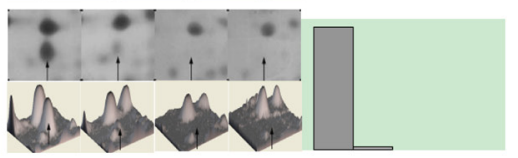

D4
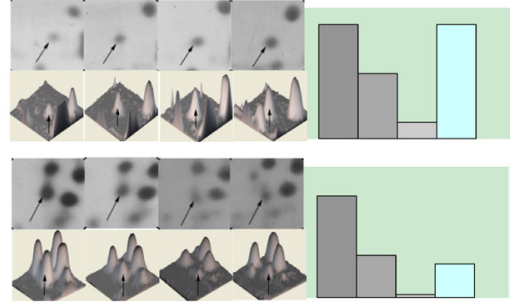

Figure 2. Selected areas of two-dimensional gels and identified spots corresponding to proteins in Bactrocera dorsalis after trichlorphon treatment. Image pairs and detection of protein spots with relative spot volumes were analyzed with the ImageMasterTM 2D Platinum software. The protein spots are classified as A (signal transduction); B (immunity); C (protein synthesis and decomposition); D (oxidative metabolism); $\mathbf{E}$ (energy metabolism); $\mathbf{F}$ (cytoskeleton protein), and $\mathbf{G}$ (other unknown functions) according to its possible functions or biological processes. For abbreviations, see legend to Figure 1.

\section{DISCUSSION}

Insecticide resistance is an inducible process rather than the function of a single enzyme or gene (Daborn et al., 2002; Soderlund and Knipple, 2003). The profiling of protein expression under trichlorphon stress in a time course mode has been recognized as a very useful approach. In the present study, 14 proteins were identified in B. dorsalis with metabolism challenge due to the application of organophosphorus pesticides. After trichlorphon treatment, at least six different functional proteins were found to be related to the resistance response. 


\section{Signal transduction proteins}

The protein labeled U1, encoding pkaap protein, was more abundant in trichlorphoninduced larvae and its expression level was reduced approximately 10 -fold $12 \mathrm{~h}$ post-treatment when compared to the blank control group. Protein pkaap is one of the signal transduction proteins that can affect $\mathrm{G}$ proteins (guanine nucleotide-binding proteins), a family of proteins involved in transmitting chemical signals outside the cells and causing chemical signal changes inside the cells. The signals are used for communication among hormones, neurotransmitters, and other signaling factors related to defensive reaction (Birnbaumer, 1990). The U5 protein is a dual-specificity tyrosine-phosphorylation-regulated kinase (DYRKs) belonging to an emerging family of protein kinases that are widely distributed in all eukaryotic organisms. The DYRK family members are involved in critical signal-regulated developmental and cellular processes, such as neurogenesis, cell proliferation, cytokinesis and cell differentiation (Lochhead et al., 2005; Gwack et al., 2006). DYRK is an antagonist to Ras/cAMP-dependent protein kinase (PKA) that can negatively regulate cell growth (Garrett et al., 1991). In Drosophila, the mutation of the DYRK family member, minibrain ( $m n b$ ), can affect post-embryonic neurogenesis, thus resulting in specific reduction in the size of optic lobes and central brain hemispheres (Tejedor et al., 1995). The human orthologue of the minibrain gene, Dyrk1A, has been mapped to be a critical region of Down syndrome and is overexpressed in Down syndrome brains, implicating a similar role for this kinase in mammalian neurogenesis as well as signal transduction functions (Guimera et al., 1999). Similarly, our results indicate that pkaap and DYRK may play a signal transduction role in the resistant adaptation to organophosphorus pesticides.

\section{Immunity-related proteins}

Protein U2 is identified as a kind of immune protein, which is similar to hemocytin in Drosophila melanogaster. Hemocytin is an immune protein found in a variety of living organisms. Its expression level increased approximately 5-fold after trichlorphon treatment for $6 \mathrm{~h}$, suggesting that immune metabolism is altered for detoxification. In addition, this protein may play an immunological role in reinforcing the importance of the clot in insect immunity (Dushay, 2009). Drosophila hemolectin gene is expressed in embryonic and larval hemocytes, and its knockdown can cause bleeding defects (Goto et al., 2003). Hemolectin double-stranded RNA exhibits a significant change in Drosophila preppie stage after low-dose irradiation exposure to X-rays (Kanao and Miyachi, 2006). Our results confirmed that hemolectin is upregulated in the larvae of $B$. dorsalis after treatment with trichlorphon. Therefore, hemolectin also plays a role in immune responses through stopping the bleeding in internal organs or tissues with trichlorphon challenges.

\section{Protein synthesis and decomposition}

The function of protein U3 is described as binding to actin. It is involved in the biological processes such as anatomical structure development, actin filament-based process, regulation of developmental process, cell projection organization and biogenesis. Cathepsin B (spot U9) is a typical cysteine protease that can cleave dietary proteins into peptides and amino acids. It is primarily expressed in the endosomal/lysosomal compartments, and its functions as 
an endopeptidase or dipeptidyl carboxypeptidase are related to the protein degradation process (Koga et al., 1991, Linke et al., 2002). It is well known that insect cathepsin B also participates in many physiological processes. For example, Bombyx mori cathepsin B is involved in the programmed cell death of silk glands and results in the histolysis of silk glands during metamorphosis (Shiba et al., 2001). Helicoverpa armigera (Noctuidae, Lepidoptera) cathep$\sin \mathrm{B}$ is involved in the degradation of yolk proteins during embryonic development (Zhao et al., 2005) and decomposition of adult fat bodies (Yang et al., 2006). The expression level of protein D3 is much higher than that expressed in 3 and $6 \mathrm{~h}$ after trichlorphon induction. It may be related to protein synthesis or decomposition during protein translation. The above three proteins reveal a lot of changes when compared to the blank control group. These results indicate that $B$. dorsalis can increase its protein synthesis and degradation after exposure to organophosphorus pesticides.

\section{Oxidative metabolism proteins}

Two protein spots (U4 and U6) were identified as GST and CG7320 in D. melanogaster. These proteins are specifically overexpressed in the larval period by the induction of trichlorphon. GSTs are a family of inducible enzymes that are important for detoxification reactions, thus performing protection for insect cells from insecticides (Hayes and Pulford, 1995). Higher expression levels of GSTs have been determined in chemical insecticide-resistant insect strains, and increased expression levels of carboxylesterases and cytochrome p450s are responsible for metabolic resistance to insecticides (Daborn et al., 2002). Our results proved that GSTs are involved in enhancing resistant metabolism. The protein CG7320, as an oxygen transporter, is involved in the biological process of expanding oxidative metabolism to fight against xenobiotics and pesticide toxicity. Increased oxidative metabolism can be an adaptive response of insects subjected to survival challenge, and can mediate detoxification that enhances the resistance of insects (Indian meal moth Plodia interpunctella) to bacteria (Bacillus thuringiensis) (Johnson, 1982). Therefore, it was clearly demonstrated that the oxidative metabolism-related proteins can be upregulated upon exposure to trichlorphon.

\section{Energy metabolism-related proteins}

Protein D1 is named as Act57B that is down-regulated under the trichlorphon stress. The possible functions of Act57B are ATP activation and protein binding. ATP is activated and then provides organisms energy produced in mitochondria of all living things. ATP binding means energy production, and energy metabolism level is related to resistance response.

\section{Cytoskeleton proteins}

The protein actin (spot D2) was detected in B. dorsalis. However, it was unstably expressed under trichlorphon stress. Actin is a highly conserved protein that is involved in the generation of contractile force in muscle as well as cell division, motility, and endocytosis and exocytosis in non-muscle eukaryotic cells (Mounier and Sparrw, 1993). Actin is also the component of the cytoskeletal system that allows for the movement of cells and cellular processes. By using a proteomics approach, insect resistance to xenobiotics and pesticides, physical wound, 
parasitoid, and microorganism attack can readily cause a change in actin expression (Candas et al., 2003; Huang et al., 2004; Nguyen et al., 2008). Taken together, an increased expression of actin can reinforce a physical barrier to better resistance from further injury.

\section{Other proteins}

The protein spots U7, U8, D4, and D5 were identified as GD10456, GK16235, GE19106, and GH20859 in the database. However, these proteins are only confirmed by conceptual translation, molecular functions and biological processes. Their functions are still unknown. However, in the present study, these proteins are regulated in resistance response to trichlorphon exposure, which is of benefit for developing strategies to combat trichlorphon toxicity.

\section{CONCLUSION}

Our experimental data demonstrate that proteins related to signaling, immunity, oxidative metabolism, protein synthesis, energy metabolism, and cytoskeleton are regulated in the resistant strains of $B$. dorsalis under conditions of organophosphorus pesticide challenge. Proteomics tools are sensitive enough to untangle proteomic alteration linked to toxic compounds at different time periods. Therefore, the metabolism of oriental fruit flies may be stimulated to generate an adaptation to trichlorphon.

\section{ACKNOWLEDGMENTS}

Research supported by the Research Project of National Public Service in Agriculture (\#200903047, \#201103026) and Scientific Research Project of Environment and Plant Protection Institute (\#2011hzs1J005, \#MACKL1005). We thank the Department of Silkworm Science, South China Agricultural University for offering the proteomics platform, and Professor Cheng Bai from the Environment and Plant Protection Institute at China Academy of Tropical Agriculture Sciences for his critical review and revision of the manuscript.

\section{REFERENCES}

Akhgari M, Abdollahi M, Kebryaeezadeh A, Hosseini R, et al. (2003). Biochemical evidence for free radical-induced lipid peroxidation as a mechanism for subchronic toxicity of malathion in blood and liver of rats. Hum. Exp. Toxicol. 22: 205-211.

Birnbaumer L (1990). G proteins in signal transduction. Annu. Rev. Pharmacol. Toxicol. 30: 675-705.

Bradford MM (1976). A rapid and sensitive method for the quantitation of microgram quantities of protein utilizing the principle of protein-dye binding. Anal. Biochem. 72: 248-254.

Candas M, Loseva O, Oppert B, Kosaraju P, et al. (2003). Insect resistance to Bacillus thuringiensis: alterations in the indianmeal moth larval gut proteome. Mol. Cell Proteomics 2: 19-28.

Daborn PJ, Yen JL, Bogwitz MR, Le Goff G, et al. (2002). A single p450 allele associated with insecticide resistance in Drosophila. Science 297: 2253-2256.

Dushay MS (2009). Insect hemolymph clotting. Cell Mol. Life Sci. 66: 2643-2650.

Fournier D, Bride JM, Hoffmann F and Karch F (1992). Acetylcholinesterase. Two types of modifications confer resistance to insecticide. J. Biol. Chem. 267: 14270-14274.

Garrett S, Menold MM and Broach JR (1991). The Saccharomyces cerevisiae YAK1 gene encodes a protein kinase that is induced by arrest early in the cell cycle. Mol. Cell Biol. 11: 4045-4052.

Goto A, Kadowaki T and Kitagawa Y (2003). Drosophila hemolectin gene is expressed in embryonic and larval hemocytes and its knock down causes bleeding defects. Dev. Biol. 264: 582-591. 
Guimera J, Casas C, Estivill X and Pritchard M (1999). Human minibrain homologue (MNBH/DYRK1): characterization, alternative splicing, differential tissue expression, and overexpression in Down syndrome. Genomics 57: 407-418.

Gwack Y, Sharma S, Nardone J, Tanasa B, et al. (2006). A genome-wide Drosophila RNAi screen identifies DYRKfamily kinases as regulators of NFAT. Nature 441: 646-650.

Hayes JD and Pulford DJ (1995). The glutathione S-transferase supergene family: regulation of GST and the contribution of the isoenzymes to cancer chemoprotection and drug resistance. Crit. Rev. Biochem. Mol. Biol. 30: 445-600.

Huang ZW, Shi P, Dai JQ and Du JW (2004). Protein metabolism in Spodoptera litura (F.) is influenced by the botanical insecticide azadirachtin. Pestic. Biochem. Physiol. 80: 85-93.

Jin T, Zeng L, Lin Y, Lu Y, et al. (2011). Insecticide resistance of the oriental fruit fly, Bactrocera dorsalis (Hendel) (Diptera: Tephritidae), in mainland China. Pest Manag. Sci. 67: 370-376.

Johnson MK (1982). The target for initiation of delayed neurotoxicity by organophosphorus esters: biochemical studies and toxicological applications. Rev. Biochem. Toxicol. 4: 141-212.

Kanao T and Miyachi Y (2006). Exposure to low-dose X-rays promotes peculiar autophagic cell death in Drosophila melanogaster, an effect that can be regulated by the inducible expression of Hml dsRNA. Mutat. Res. 595: 60-68.

Koga H, Yamada H, Nishimura Y, Kato K, et al. (1991). Multiple proteolytic action of rat liver cathepsin B: specificities and $\mathrm{pH}$-dependences of the endo- and exopeptidase activities. J. Biochem. 110: 179-188.

Linke M, Herzog V and Brix K (2002). Trafficking of lysosomal cathepsin B-green fluorescent protein to the surface of thyroid epithelial cells involves the endosomal/lysosomal compartment. J. Cell Sci. 115: 4877-4889.

Lochhead PA, Sibbet G, Morrice N and Cleghon V (2005). Activation-loop autophosphorylation is mediated by a novel transitional intermediate form of DYRKs. Cell 121: 925-936.

Mounier N and Sparrow JC (1993). Muscle actin genes in insects. Comp. Biochem. Physiol. B 105: 231-238.

Nguyen TT, Boudreault S, Michaud D and Cloutier C (2008). Proteomes of the aphid Macrosiphum euphorbiae in its resistance and susceptibility responses to differently compatible parasitoids. Insect. Biochem. Mol. Biol. 38: 730-739.

Pan ZP, Lu YY, Zeng L and Zeng XN (2008). Development of resistance to trichlorophon, alphamethrin, and abamectin in laboratory populations of the oriental fruit fly, Bactrocera dorsalis (Hendel) (Diptera:Tephritidae). Acta Entomol. Sin. 51: 609-617.

Ranson H, Claudianos C, Ortelli F, Abgrall C, et al. (2002). Evolution of supergene families associated with insecticide resistance. Science 298: 179-181.

Shevchenko A, Wilm M, Vorm O and Mann M (1996). Mass spectrometric sequencing of proteins silver-stained polyacrylamide gels. Anal. Chem. 68: 850-858.

Shiba H, Uchida D, Kobayashi H and Natori M (2001). Involvement of cathepsin B- and L-like proteinases in silk gland histolysis during metamorphosis of Bombyx mori. Arch. Biochem. Biophys. 390: 28-34.

Soderlund DM and Knipple DC (2003). The molecular biology of knockdown resistance to pyrethroid insecticides. Insect. Biochem. Mol. Biol. 33: 563-577.

Song KH, Jung MK, Eum JH, Hwang IC, et al. (2008). Proteomic analysis of parasitized Plutella xylostella larvae plasma. J. Insect Physiol. 54: 1270-1280.

Stark JD (2005). How closely do acute lethal concentration estimates predict effects of toxicants on populations? Integr. Environ. Assess. Manag. 1: 109-113.

Steiner LF (1957). Field evaluation of oriental fruit fly insecticides in Hawaii. J. Econ. Entomol. 50: 16-24.

Tejedor F, Zhu XR, Kaltenbach E, Ackermann A, et al. (1995). minibrain: a new protein kinase family involved in postembryonic neurogenesis in Drosophila. Neuron 14: 287-301.

Tu CJ, Dai J, Li SJ, Sheng QH, et al. (2005). High-sensitivity analysis of human plasma proteome by immobilized isoelectric focusing fractionation coupled to mass spectrometry identification. J. Proteome. Res. 4: 1265-1273.

Yang XM, Hou LJ, Dong DJ, Shao HL, et al. (2006). Cathepsin B-like proteinase is involved in the decomposition of the adult fat body of Helicoverpa armigera. Arch. Insect Biochem. Physiol. 62: 1-10.

Ye H and Liu JH (2005). Population dynamics of the oriental fruit fly, Bactrocera dorsalis (Diptera: Tephritidae) in the Kunming area, southwestern China. Insect Sci. 12: 387-392.

Zhao XF, An XM, Wang JX, Dong DJ, et al. (2005). Expression of the Helicoverpa cathepsin B-like proteinase during embryonic development. Arch. Insect Biochem. Physiol. 58: 39-46.

Zhou H, Dai J, Sheng QH, Li RX, et al. (2007). A fully automated 2-D LC-MS method utilizing online continuous pH and RP gradients for global proteome analysis. Electrophoresis 28: 4311-4319. 